\title{
O desenho como meio primevo de conhecimento
}

\author{
José Maria da Silva Lopes*
}

Resumo O presente artigo discorre sobre algumas questões que se fizeram presentes no Colóquio Desenho + Projecto: Diálogo entre São Paulo e Porto ${ }^{1}$ e aborda o debate sobre os meios digitais e a prática do desenho. Apresenta o programa e a metodologia da Disciplina de Desenho ministrada na Faculdade de Arquitectura da Universidade do Porto, onde o desenho reforça a identidade do Curso, comparecendo como instrumento fundamental no processo projetivo.

Palavras-chave: desenho, Faculdade de Arquitectura da Universidade do Porto, projecto.

\section{Drawing as the primeval medium of knowledge}

Abstract This article discusses some of the issues that were present at the Design + Project Colloquium: Dialogue between São Paulo and Porto, and deals the debate on digital media and the practice of free-hand drawing. It presents the program and the methodology of the Drawing's Discipline taught at the Faculty of Architecture of the University of Porto, where the design reinforces the identity of the Course, appearing as a fundamental instrument in the projective process.

Key words: free-hand drawing, Faculty of Architecture of the University of Porto, project.

\section{El diseño como medio primario de co- nocimiento}

Resumen El presente artículo discurre sobre algunas cuestiones que se hicieron presentes en el Coloquio Diseño + Proyecto: Diálogo entre São Paulo y Porto y aborda el debate sobre los medios digitales y la práctica del diseño a mano alzada. Se presenta el programa y la metodología de la Disciplina de Diseño impartida en la Facultad de Arquitectura de la Universidad de Porto, donde el diseño refuerza la identidad del Curso, apareciendo como instrumento fundamental en el proceso proyectivo.

Palavras clave: dibujo, Facultad de Arquitectura de la Universidad de Porto, proyecto. 
Comentava, com algum pesar mais ou menos nítido, o Arquitecto Renato Luiz Sobral Anelli ${ }^{2}$, no decorrer de uma breve conversa acerca da utilização algo desgovernada dos meios de escrita digitais, que: "Actualmente, ninguém escreve em papel. Utilizam-se ferramentas digitais". Acerca do assunto em causa, sou de opinião que o problema que se pode levantar não é escrever em papel ou escrever com recurso a suportes e ferramentas digitais. O problema é saber escrever. Para quem não sabe escrever, tanto faz. Todas as ferramentas levantarão obstáculos. As complexidades inerentes acto de escrever serão as mesmas e os erros semelhantes, independentemente do suporte. Quem tiver dificuldades em articular um discurso coerente utilizando a caneta e o papel, terá as mesmas dificuldades se servir de outros meios, sejam, ou não, digitais.

Com o Desenho, a situação é análoga. Se um indivíduo tiver uma prática continuada de desenho e uma consciência clara dos diversos processos e mecanismos que o mesmo implica, abordará os meios de representação digitais com uma facilidade maior do que o individuo para quem o desenho, servido pelos meios tradicionais, seja uma matéria nebulosa, ou mesmo desconhecida.

Por outro lado, escrever à mão ou desenhar à mão implica um estabelecer de relações neuronais, intelectuais, fisiológicas ou afectivas muito distintas das estabelecidas no acto de desenhar com recurso aos meios digitais.

Guardo, com afecto, todos os caderninhos onde vou escrevendo, tirando notas, e apontamentos diversos, frequentemente articulados com desenhos. Tenho uma colecção relativamente grande que, paulatinamente, vai acumulando mais caderninhos, ano após ano. Sei onde estão e o que contêm. São pequenos pedaços de memória. Neles posso rever todo o processo da escrita, todas as hesitações, as rasuras, os erros, os arrependimentos, o limar de arestas, a construção de um sentido, o arrumar coerente, quanto possível, do assunto, em suma, o processo de escrita. Revisito, também, os desenhos que os enlaçam. Que os complementam. Encanto-me a observar como texto e desenho se articulam numa dança impossível de traduzir por meios digitais.

* José Maria da Silva Lopes é artista plástico com ênfase em escultura, professor doutor da Faculdade de Arquitectura da Universidade do Porto.

${ }^{1}$ Colóquio Desenho + Projeto, realizado no IAU.USP, São Carlos em abril de 2013.

2 Professor Doutor do IAU USP, palestrante convidado do Colóquio Desenho + Projeto, realizado no IAU.USP, 2013. Dos textos elaborados em suporte digital, e dos quais que vou fazendo Save para um disco externo, perdi o processo e a memória do fazer. Apenas tenho um resultado final distante do empenho do acto gerador. Não os revisito. São tristes encadeamentos de zeros e uns tornados aparições.

Todo o registo escrito à mão tem, ele próprio, uma imagem. Uma imagem específica, detentora directa das particularidades gráficas do autor. A normalização imposta pelos meio digitais impede tal acontecimento. Com o Desenho, a situação é análoga. Se colocarmos em confronto dois cadernos de desenhos de pessoas distintas, há a garantia imediata das dissemelhanças determinadas pelas particularidades gráficas impostas pelos seus autores. 
3 Não posso, todavia, ser ingénuo Notarei, certamente, conteúdos distintos.
4 Apreciações realizadas pelo Arquitecto Francisco Barata durante a moderação que efectuou no Colóquio Desenho + Projecto: Diálogo entre São Paulo e Porto. Mesa 1 (10:00-13:30hs) - O Olhar do Arquitecto sobre o Desenho. 20-3-2013.
Trata-se, em suma, de expressão, das singularidades de registo que perfilam, em última instância, a autoria. A identidade conferida pelo registo à mão é assunto fundamental do Desenho. Os meios digitais nivelam as imagens produzidas transformando a possibilidade do indivíduo no enevoamento da normalização colectiva. Os textos, e mesmo os desenhos, produzidos através de meios digitais são, enquanto imagem, todos iguais. Não consigo distinguir uma página de escrita de outra. Não distingo uma possibilidade de registo de outra. Somos reduzidos a uma espécie de Arial 12 a um espaço e meio. Quando utilizamos meios digitais perde-se aquilo que poderei nomear como o carácter do caractere. Tudo é igual. Normalizado. Formatado 3 .

De modo análogo à escrita, se dispusermos em cotejo uma série de renders de projectos de arquitectura o problema primeiro recai sobre a aparência idêntica das imagens. Não distingo identidades gráficas. Não revejo autores. Teria que observar um sem número de imagens para poder distinguir tipologias de forma, de assunto ou, mais concretamente, de projecto. O conteúdo pode, naturalmente, ser identificativo, mas a vinculação autoral proporcionada pelo fazer à mão desparece.

Temo que, a curto prazo, o acto de escrita, entendido enquanto gesto de registo com caneta sobre papel, possa desaparecer. Atrevo-me a pequenas especulações: se daqui a alguns anos um miúdo escrever através dos meios tradicionais será, certamente, alvo de atenções diversas. Fazer surgir qualquer coisa no papel através de um pincel e tinta, ou um qualquer outro instrumento de registo que não o digital, será algo de, realmente, extraordinário. Ilusionismo, magia, um fenómeno.

Tornar aparente na alvura do suporte, partindo do nada, apenas com a mão e um instrumento, letras desenhadas, é, para todos os efeitos, surpreendente.

\section{II}

\section{A Escola de Arquitectura do Porto é a Escola de Arquitectura do Porto. Não outra.}

A expressão Escola de Arquitectura do Porto deve ser entendida, no presente contexto, como uma expressão de carácter genérico, actualmente algo mediatizada, que tem como referente a Faculdade de Arquitectura de Universidade do Porto. Pretende-se, com a expressão, pôr em evidência as particularidades de um ensino que, pelas suas características específicas enformam a noção de Escola ou, mesmo, de Academia. Não me detenho, na economia deste texto, acerca do caleidoscópio de factores que me permitem partilhar da opinião do Arquitecto Francisco Barata ${ }^{4}$ ao avançar o termo Escola. Apesar de algumas apreciações tenuemente divergentes, a Faculdade de Arquitectura da Universidade do Porto é detentora de uma identidade muito peculiar, construída ao longo dos anos e alicerçada em saberes, também eles, particulares. Há, na realidade, uma ideia de Escola. Neste sentido, quem escolher estudar na FAUP não o deverá fazer aleatoriamente ou de modo ligeiro.

É curioso observar como os alunos provenientes do estrangeiro solicitam, no leque das opções possíveis, as Unidades Curriculares de Desenho. A procura pelo Desenho excede, frequentemente, a capacidade logística. Os candidatos são, amiúde, em maior número do que as reais capacidades de integração. A procura pelo Desenho, 
5 Considero que o Desenho é, em última instância, uma necessidade intuitiva, profundamente biológica e enraizada nas nossas heranças genéticas.
6Devo notar que os alunos continuam a desenhar mesmo quando o Desenho deixa de fazer parte do currículo escolar. Enviam-me, com frequência, desenhos. Colocam-me dúvidas, perplexidades, hesitações e solicitações de apreciação. Em suma, as suas inquietações enquanto pessoas com capacidade de pensar pelo Desenho. O Desenho é, neste sentido, um processo de autoconsciência, de autoconhecimento.

7 Debater-me-ei, em particular, com questões relacionadas com a Unidade Curricular Desenho I. Todavia, tal não invalida que, sempre que seja oportuno, não possa estabelecer breves considerações acerca de Desenho Il e de Figura Humana e Representação do Espaço. ou mais propriamente o Desenho fará, certamente, parte dessa identidade maior que é FAUP.

O aluno quer desenhar. Quer muito desenhar. Por vezes não sabe bem porquê5. Outros têm a consciência plena de que o Desenho é um saber que lhes faz falta na sua formação enquanto arquitectos e enquanto pessoas.

No início de cada ano lectivo, os alunos no regime de mobilidade realizam uma prova preliminar de desenho. Sucintamente, a prova visa apurar competências pré-adquiridas que permitam a colocação dos candidatos em anos adequados.

Devo referir, pela peculiaridade derivada de uma procura acentuada, que, dentro do leque de ofertas na área científica do Desenho, a Unidade Curricular de Figura Humana e Representação do Espaço se encontra entre as mais solicitadas. Para lá das questões intrínsecas ao desenvolvimento do projecto em arquitectura, sente-se a necessidade que o aluno tem em procurar saberes relativos à representação do corpo humano, de entender o Homem enquanto motor e medida de inquietações projectuais. Esta procura é um indício feliz. É, similarmente, um sintoma das preocupações dos alunos relativamente à necessidade do Desenho e do seu autoconhecimento.

Para mim, enquanto professor de Desenho, é extremamente gratificante verificar esse querer.

\section{III}

O Desenho é uma ferramenta operativa transversal à globalidade das Unidades Curriculares do Curso de Mestrado Integrado (MIARQ) da FAUP. Desenha-se, como seria expectável, nas Unidades Curriculares Desenho I, Desenho /l e em Figura Humana e Representação do Espaço, mas, também, em Projecto, em Geometria, em História da Arte, em CAAD, em Construção... ${ }^{6}$

Enquanto professor de Desenho na FAUP tenho a responsabilidade e o prazer de coordenar a Unidade Curricular Desenho I. Partilho, ainda, com o Professor Vítor Silva, a docência da Unidade Curricular Figura Humana e Representação do Espaço ${ }^{7}$.

A Unidade Curricular Desenho I tem com um dos seus principais objectivos promover a representação e o conhecimento do mundo visível e das imagens mentais. Encontra-se, particularmente, vinculada à percepção e à representação do real através do registo gráfico manual, procurando proporcionar aos alunos ferramentas que Ihes permitam desenvolver capacidades de observação, de representação, de memorização, de expressão, de organização e de desenvolvimento projectual (ARNHEIM, 1984).

Pretende-se, neste sentido, que os alunos desenvolvam as competências necessárias para perceber, conceber e executar imagens. Para lá do carácter operacional ou de ferramenta o Desenho deseja, outrossim, que os alunos se possam identificar emocionalmente com o trabalho que vão desenvolvendo. O desenho deverá proporcionar satisfação, ser um objecto que ocasiona prazer. O Desenho não deverá ser encarado apenas como um princípio instrumental mas, também, como um princípio artístico. O prazer gerado 
Figuras 1 e 2: Trabalhos da disciplina de desenho da FAUP. Fonte: Acervo do autor, 2012. pela execução gráfica e a fruição estética pelo trabalho produzido são, naturalmente, incentivados (MASSIRONI, 1983).

O programa de Desenho I organiza-se em torno de três fases que abordam quatro temas gerais: $\mathbf{O}$ Espaço Externo, $\mathbf{O}$ Espaço Interno, O Objecto e $\boldsymbol{O}$ Corpo Humano.

A primeira fase, Percepção e Reconhecimento, debruça-se, essencialmente, sobre questões elementares do Desenho de observação e da percepção métrica (CÂMARA MUNICIPAL DE LISBOA, 1993).

Inicialmente, aluno é convidado a olhar para objectos facilmente mensuráveis e manuseáveis. Evita-se o contacto com problemas complexos de articulações espaciais, de quantificações métricas da paisagem urbana ou, ainda, as relações de carácter sensível como os valores de luz e sombra ou a cor. A questão é simples: solicita-se que, perante um objecto, o aluno o possa medir. Em suma, trata-se de perceber e representar relações de altura, de largura e de profundidade e como as partes se organizam entre si e com o todo. O desenho é, nesta fase, essencialmente estrutural e analítico (Figs. 1 e 2). Os meios de realização são elementares. Privilegiam-se os lápis de grafite, entre o $2 \mathrm{~B}$ e o 4B, e folhas brancas de papel de $125 \mathrm{gr} / \mathrm{m} 2$, entre o $\mathrm{A} 5$ e o $\mathrm{A} 3$.

Um dos primeiros problemas que abordamos com os alunos é a ocupação da folha. É frequente o aluno não adequar a desenho que executa às dimensões do suporte. Os motivos podem ser os mais diversos: dificuldade em resolver questões de escala, problemas de proporção e de relações entre partes, falta de conhecimento e inadequação aos meios expressivos, receio de errar, timidez, ...

Alguns temas, como as Árvores, permitem aos alunos alguma flexibilidade. Os erros de relações métricas são frequentes nestes desenhos. Todavia, pela natureza e pela complexidade do objecto, a aparência gráfica sobrepõe-se, frequentemente, ao rigor das medidas.
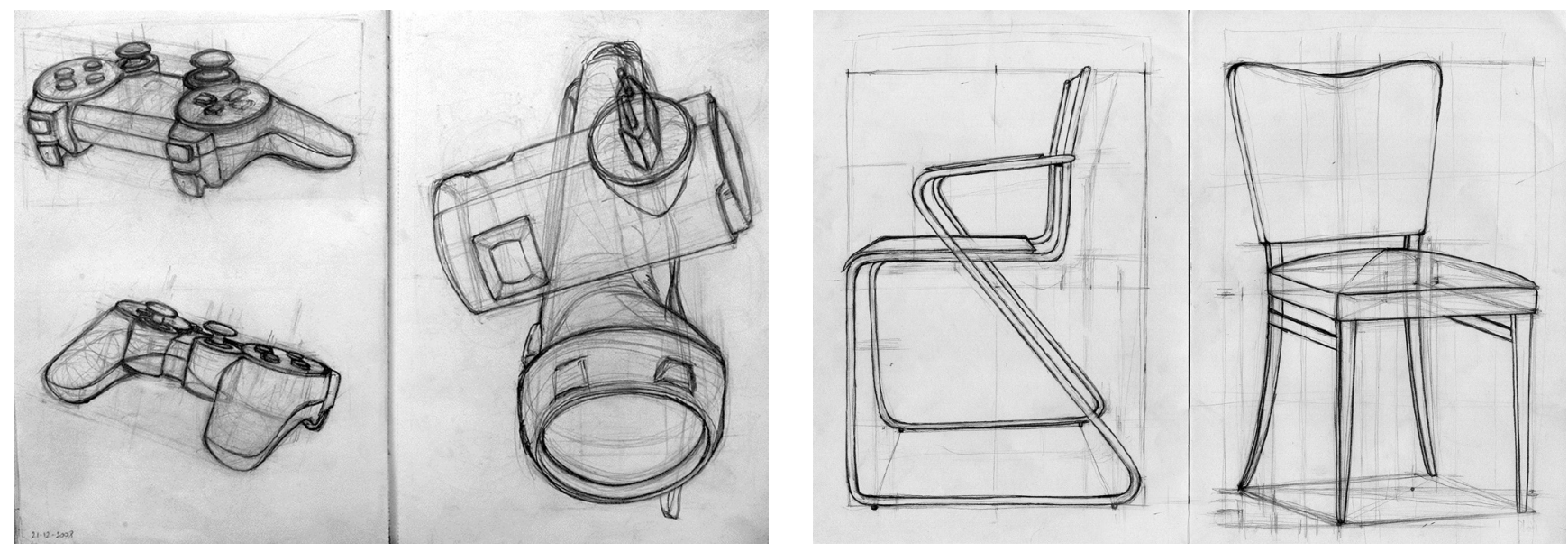
O aluno sente alguma satisfação com os resultados, não porque não tenha conhecimento das falhas, mas por que estas não são evidentes. O erro, não é, neste caso, uma derrota para o aluno. Por seu turno, em objectos com contornos definidos, em peças de características geométricas ou na representação perspéctica, as falhas na observação e na quantificação são, de imediato, reconhecidas. Naturalmente, o aluno é acompanhado, pedagogicamente, na descoberta dos processos do desenho. Consideramos um pressuposto fundamental: desenhar implica um método de elaboração gráfica de imagens assente num processo contínuo de hipótese e correcção. Todavia, os alunos não apagam os desenhos. Os registos gráficos revelam o processo de representação gráfica do real: a detecção do erro, a reavaliação e a reformulação.

O aluno é, outrossim, levado a desenhar do geral para o particular. Este método favorece a recolha de informação por etapas, a organização do campo de visão e a representação controlada da realidade. As sessões teóricas complementam os saberes derivados da prática e lançam as questões e os temas de estudo

Ao longo da fase de trabalho, os assuntos e os temas do Desenho complexificam-se. Dos objectos de dimensão reduzida transita-se para objectos de dimensão média, como as cadeiras (Figuras 1 e 2).

Estabelecem-se as primeiras relações espaciais a partir de composições de figuras geométricas. Introduz-se o aluno nos problemas da representação perspéctica (Figuras 3 e 4).

Deve notar-se que o registo gráfico é, fundamentalmente, linear. Os problemas levantados são de relações construtivas e métricas. Apenas no final da Fase I o aluno é confrontado com problemas de relações de claro-escuro. Todavia, pressupõe-se, sempre, que o desenho seja, previamente, medido. Neste sentido, os desenhos finais da primeira fase de trabalho constituem-se como o reflexo tangível da procura de uma percepção mensurável da realidade à qual se alia uma dominante sensível que procura, nos valores de luz e sombra, a empatia.

A segunda fase de trabalho, Reconhecimento e Expressão, permite a continuidade da abordagem dos problemas de percepção e de representação do real, enveredando por questões relacionadas com a expressão e a aquisição de uma intencionalidade gráfica. Ampliam-se os temas e variam-se os instrumentos, os formatos e a duração dos exercícios. É introduzida a Cor e a Figura Humana (Figura 5).

Solicita-se ao aluno que experimente hipóteses preceptivas distintas relacionando-as com hipóteses gráficas diferenciadas: os Modos do Desenho.

Consideramos quatro tipologias de registo gráfico: o Esquisso, o Detalhe, o Contorno e o Esboço. Cada modo estabelece condições particulares que determinam disposições cognitivas e gráficas específicas. O desempenho cognitivo e a acção gráfica de registo encontram-se condicionados por duas circunstâncias principais: a duração do exercício e o instrumento. Cada Modo do Desenho origina, por sua vez, resultados com características próprias a nível de índices de representação e de articulação de elementos plásticos (HALE, 1989). 

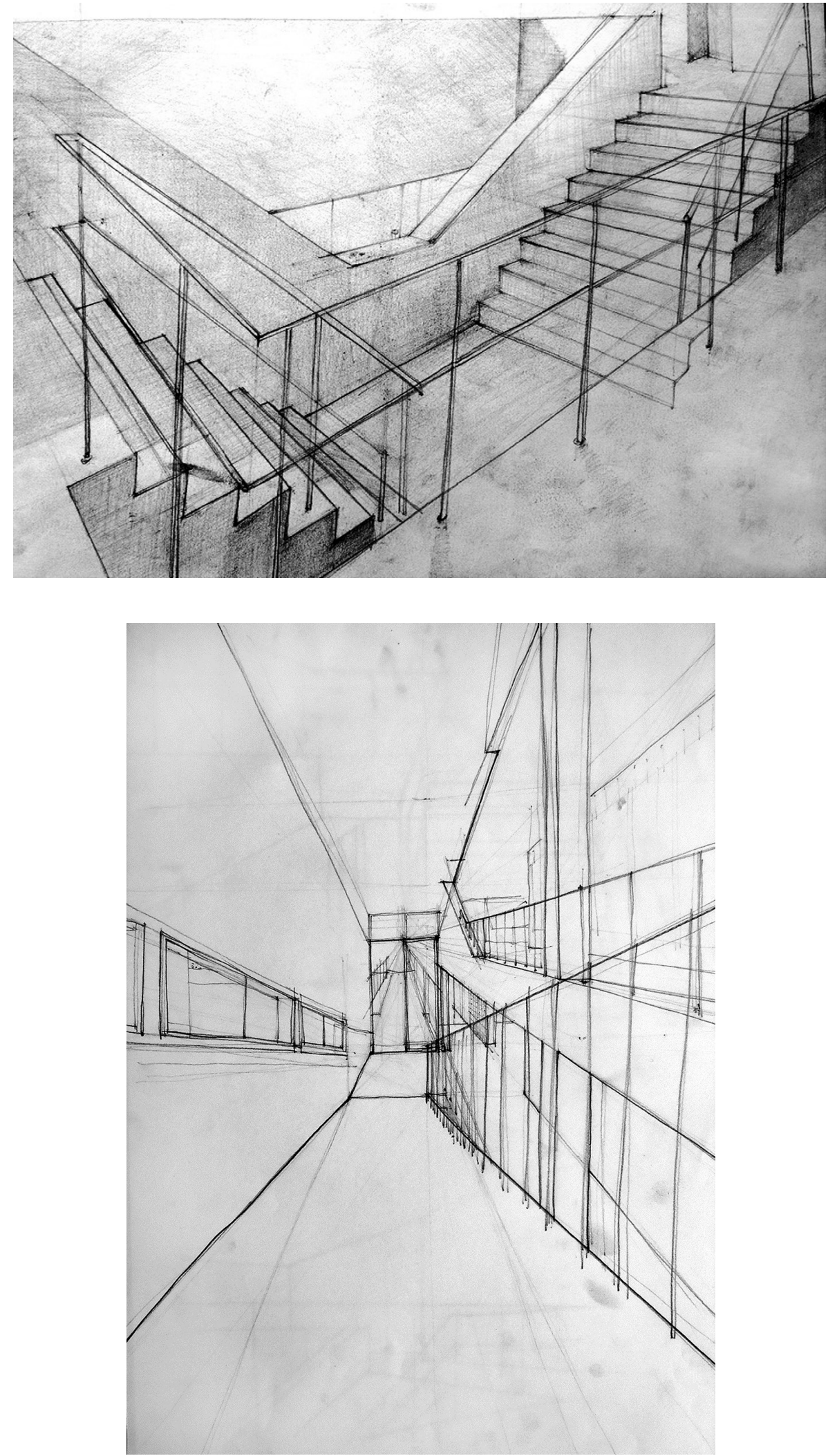

Figuras 3 e 4: Trabalhos da

disciplina de desenho da FAUP.

Fonte: Acervo do autor, 2012 
Figura 5: Trabalho da disciplina de desenho da FAUP. Fonte: Acervo do autor, 2012.

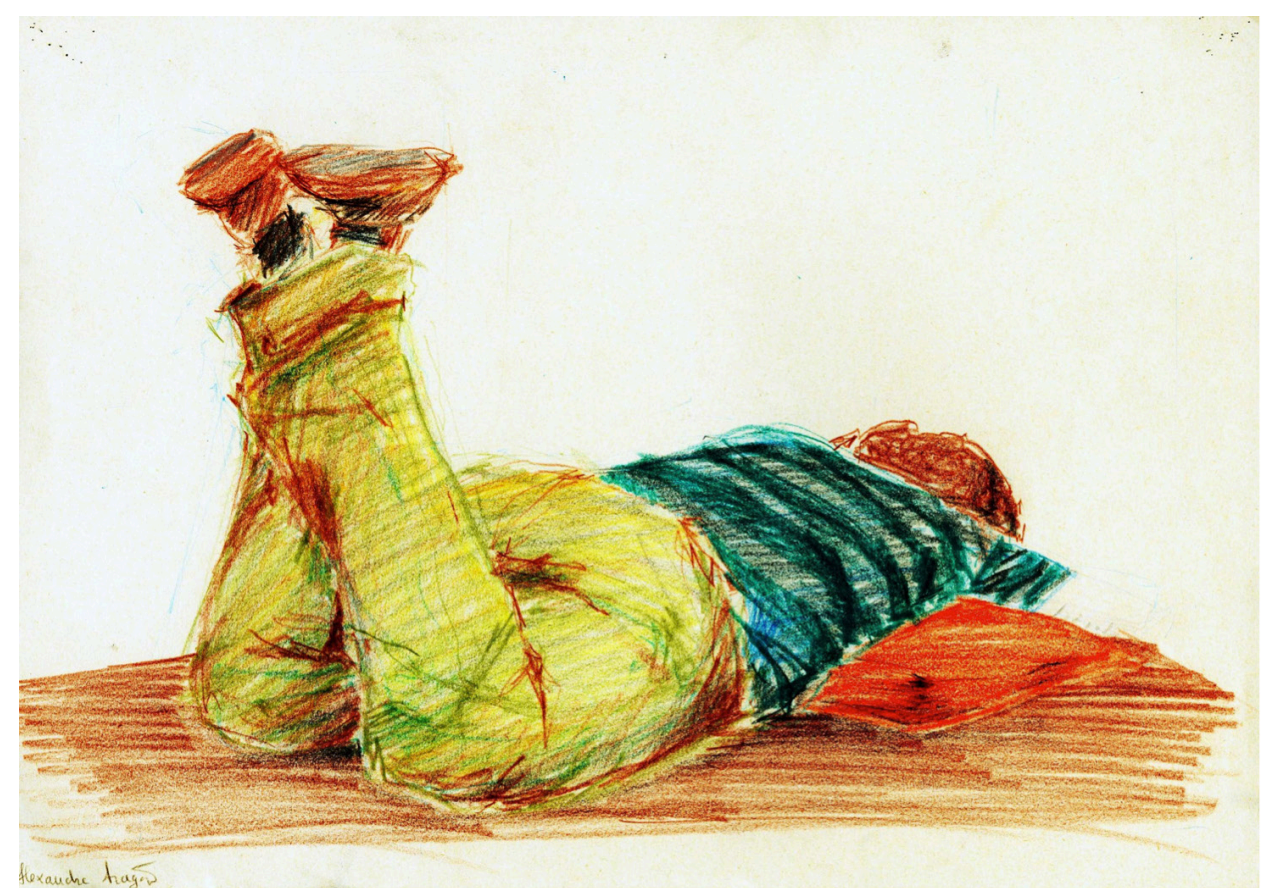

O Esquisso é um regime de registo rápido. A escala do desenho é, geralmente, reduzida. Os gestos são económicos quanto possível, não sendo por isso um modo em que a relação do real com a imagem permita um processo de hipótese e correcção. O Esquisso privilegia, frequentemente, a comunicação com o autor.

O Detalhe é um modo que opera quase por oposição ao Esquisso. A duração é longa, originando imagens com elevados índices de representações do geral e do particular. É descritivo e enumerativo. Permite, um processo de construção da imagem controlado pela hipótese e pela correcção. O Detalhe implica uma predisposição perceptiva ordenada e meticulosa.

No Contorno a acção gráfica é rigorosamente controlada. O traço é contido e contínuo. Não permite ensaios ou correcções. Quando se erra tem que se assumir o erro ou repetir o desenho. A representação foca-se no particular e no detalhe. É um tipo de registo que é, simultaneamente, origem e conclusão (Figura 6).

No Esboço promove-se uma estratégia de investigação de hipóteses visuais, de ensaio e de correcção. O registo parte do geral para o particular. Favorece-se o aumento da escala da imagem. A duração é média. O Esboço favorece princípios de observação e de representação de valores sensíveis como a luz e a cor (Figuras 7 e 8).

Penso que a grande dissemelhança que se pode estabelecer entre os diversos Modos do Desenho, quando tidos como modos puros/canónicos, reside essencialmente na opção efectuada entre o uso da mancha ou do uso linha como meios de expressão gráfica.

O desenho que utiliza a linha como factor dominante, é um desenho que reflecte uma atitude de abstracção para com a realidade. Raramente se encontram linhas 
Figura 6: Trabalho da disciplina de desenho da FAUP. Fonte: Acervo do autor, 2012. na natureza. Na maior parte das vezes apenas somos confrontados com planos, volumes, ou relevos. Deste modo, ao captarmos a realidade através da linha estamos a estabelecer um sistema, ou um processo, que opera através de uma interpretação abstracta, racional e métrica dessa mesma realidade.

Por seu turno, o desenho que se serve essencialmente da mancha é quase irracional. O desenhador estabelece uma relação de empatia para com a realidade circundante que the ofusca a capacidade de captar determinados tipos de fenómenos ligados à percepção métrica do espaço ou dos objectos privilegiando fenómenos como a luz ou a sombra. A mancha é também o meio ideal para captar situações sobre as quais não temos um domínio preciso como determinados fenómenos atmosféricos passageiros ou situações de grande agitação ou movimento.

Neste sentido, a linha é o meio gráfico privilegiado pelo desenho de contorno assim como o esboço privilegia a mancha. O desenho de contorno é controlado, perceptivo e preciso ao ínfimo pormenor. O esboço é organizador, sensitivo e, não raras vezes, impreciso. Enquanto que o contorno é princípio e fim simultaneamente o esboço prepara a abordagem das formas e das ideias.

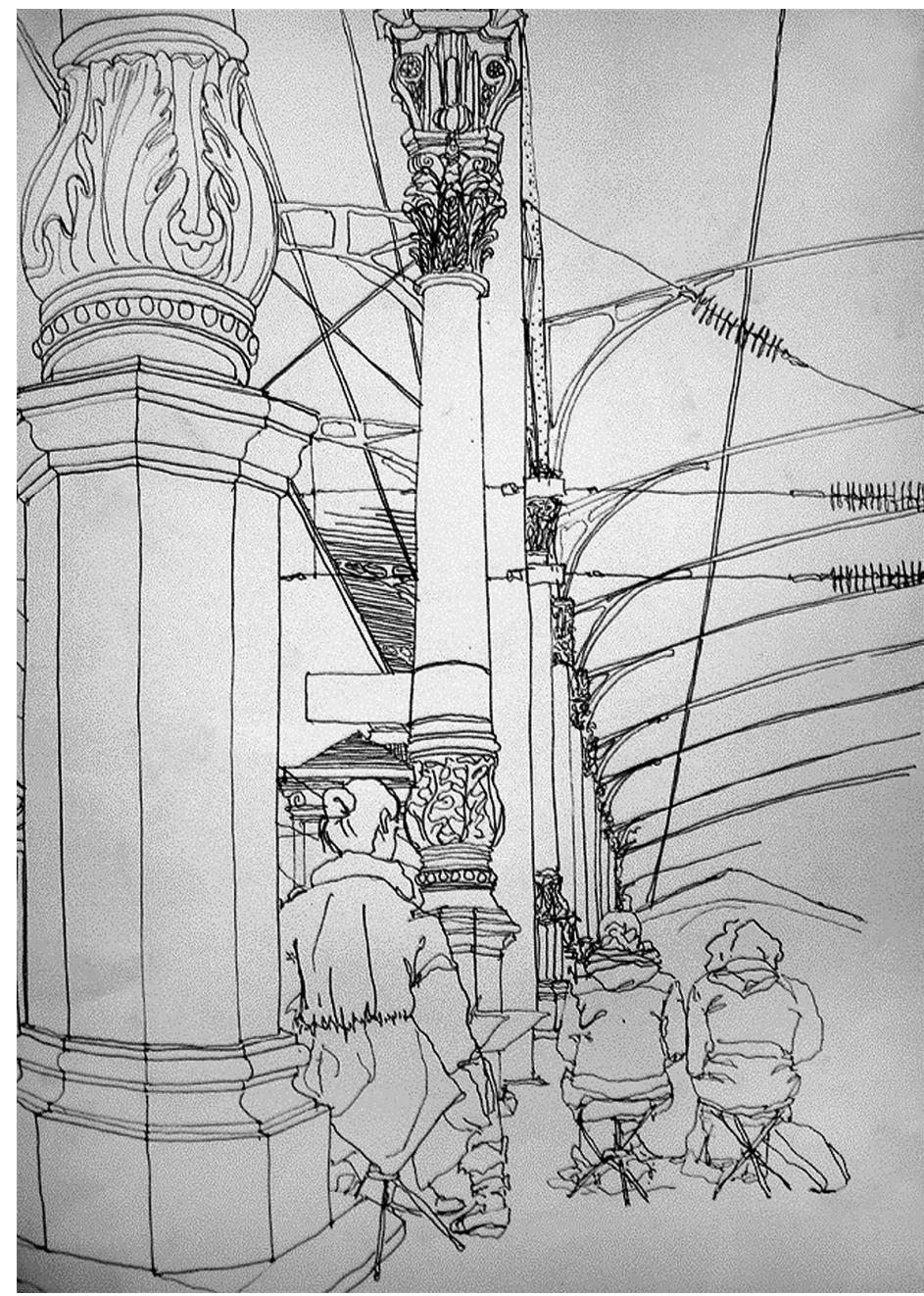



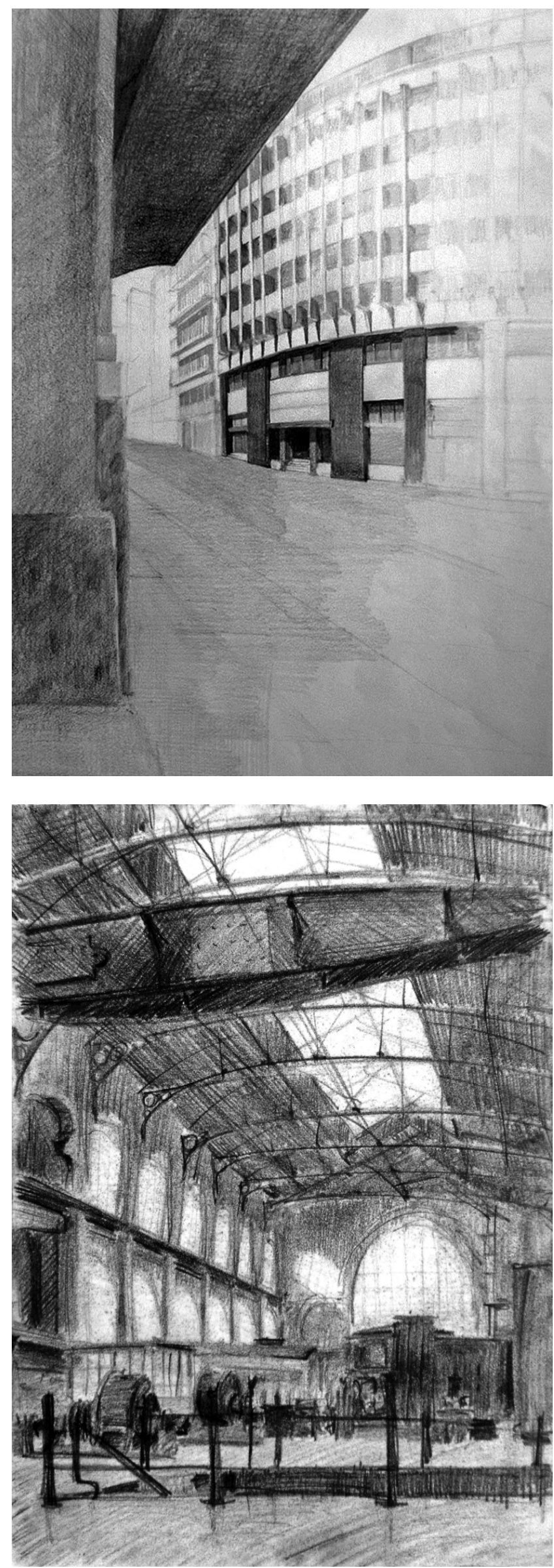

Figuras 7 e 8: Trabalhos da disciplina de desenho da FAUP. Fonte: Acervo do autor, 2012. 
Enquanto conceito, o desenho de contorno implica um sistema fechado. Por outro lado, o conceito de esboço pressupõe um sistema em aberto. O esboço em si próprio é o resultado de um acto de suspensão. Através do esboço, o desenhador aguça o apetite ao observador criando-lhe expectativas pelo simples facto de suspender o desenho.

O desenho de contorno surge como o resultado de um grande esforço de observação. É um acto cansativo. Não se pode parar, não se pode corrigir.

Considerando a situação de aprendizagem, o aluno não tem, à partida, capacidades de percepção e correspondentes mecanismos de realização gráfica que lhe permitam a execução satisfatória de desenhos de contorno. A questão que se põe é a seguinte: será que o desenho de contorno permite desenvolver no aluno capacidades de percepção e meios gráficos que lhe permitam a autonomia suficiente para se expressar, não só no presente como posteriormente, através do desenho? Alargando a questão: será que algum dos outros modos de desenho - esquisso, contorno, esboço e detalhe - quando utilizados canonicamente o permitem? A situação de esboço permite corrigir, aproximar, parar. Contudo é imprecisa e parca de informação, tal como o é, noutra medida, o esquisso. Por seu turno, a construção metódica, estruturada e analítica da realidade constitui a essência do desenho de detalhe. O contorno é perceptivamente abstracto. Deste ponto de vista, o desenho de detalhe talvez seja o modo gráfico que melhor permite ao aluno a captação concreta de medidas, relações de distância, de alturas ou profundidades. Todavia, o que se ganha em rigor perde-se em expressão gráfica espontânea. Os modos do desenho completam-se e completam o aluno (GÓMEZ MOLINA, 1995).

A terceira fase de trabalho, Expressão e Consideração, pretende consolidar todo o aprendizado anterior promovendo a valorização e a autonomização das capacidades perceptivas e de registo do real. Fomenta-se a intencionalidade conceptual, programática e poética do estudante, assim como a capacidade em compor imagens. Pretende-se, ainda, que os trabalhos realizados nesta fase sejam reveladores de tipologias de registo gráfico que permitam distinguir indivíduos.

Neste sentido, é da vontade da Unidade Curricular Desenho / que o aluno seja portador de um pensar próprio por Desenho e em Desenho (Figuras 9-13).

\section{IV}

Sou de opinião convicta de que o desenho elaborado pelos meios de registo tradicionais é instrumento fundamental no processo de projectar em arquitectura. $\mathrm{O}$ Desenho à mão, para além das capacidades estruturante, operativa, construtiva e, absolutamente, mediadora na actividade do arquitecto, deve ser entendido como um meio primevo de conhecimento. O desenho tem essa particularidade maravilhosa de permitir conhecer. Ao desenhar à mão, conheço e conheço-me. O desenho desenha, desenha-se e desenha-nos. Indubitavelmente, o Eu é sempre vertido na alva candura das folhas de papel.

\section{V}

Nulla dies sine linea. 

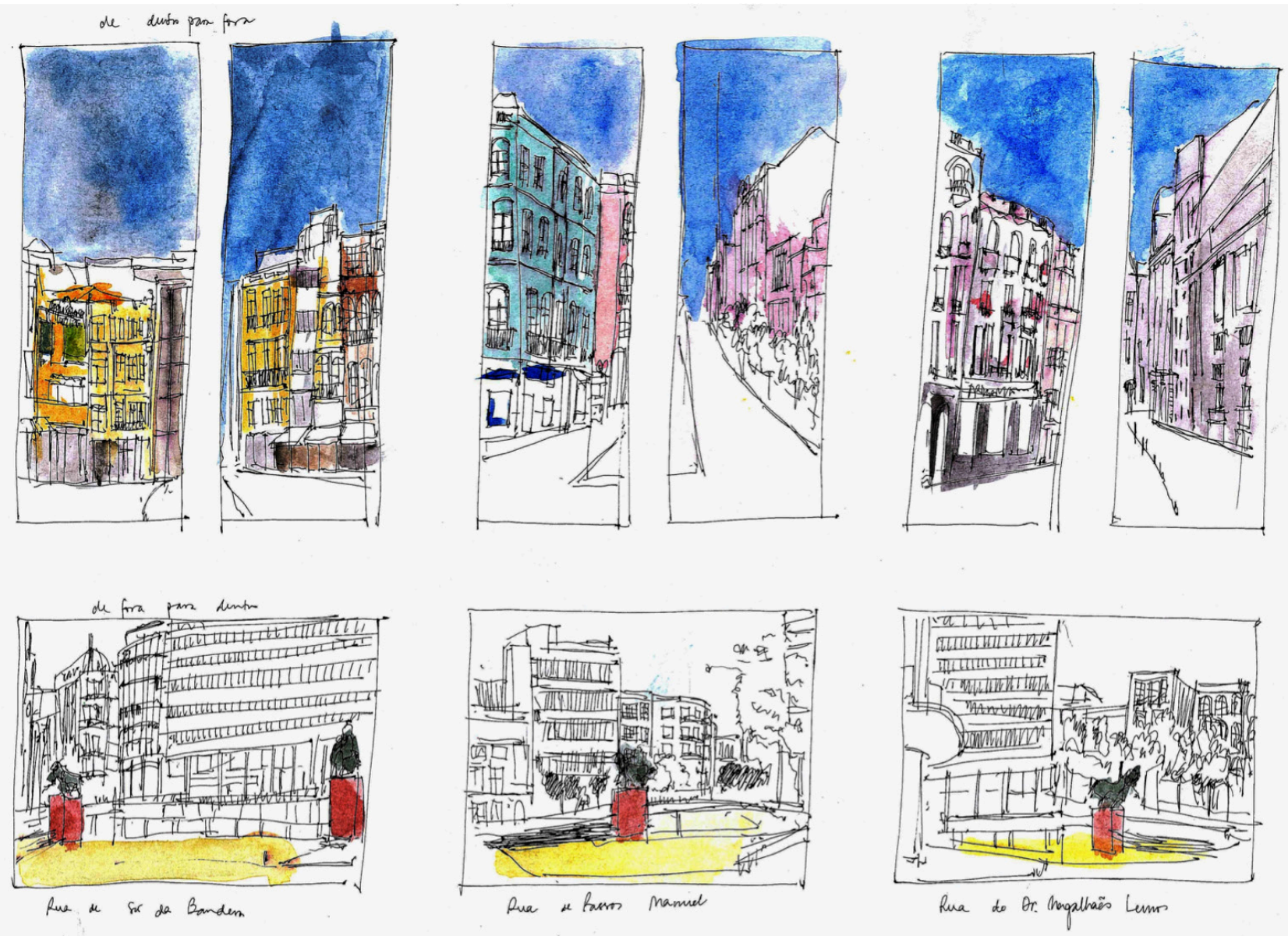

Figura 9: Trabalho da disciplina de desenho da FAUP. Fonte: Acervo do autor, 2012. 


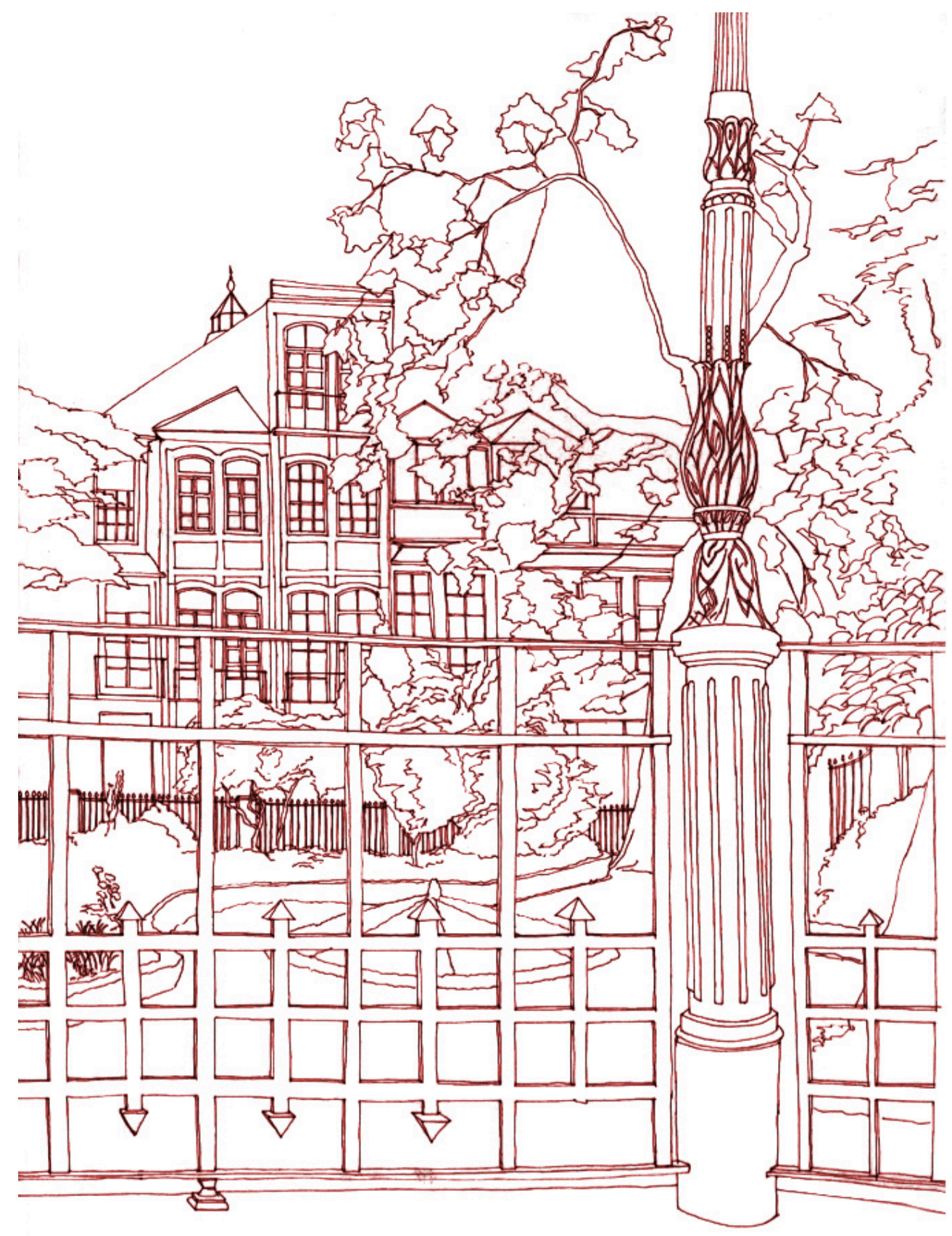

Figura 10: Trabalho da disciplina de desenho da FAUP. Fonte: Acervo do autor, 2012. 

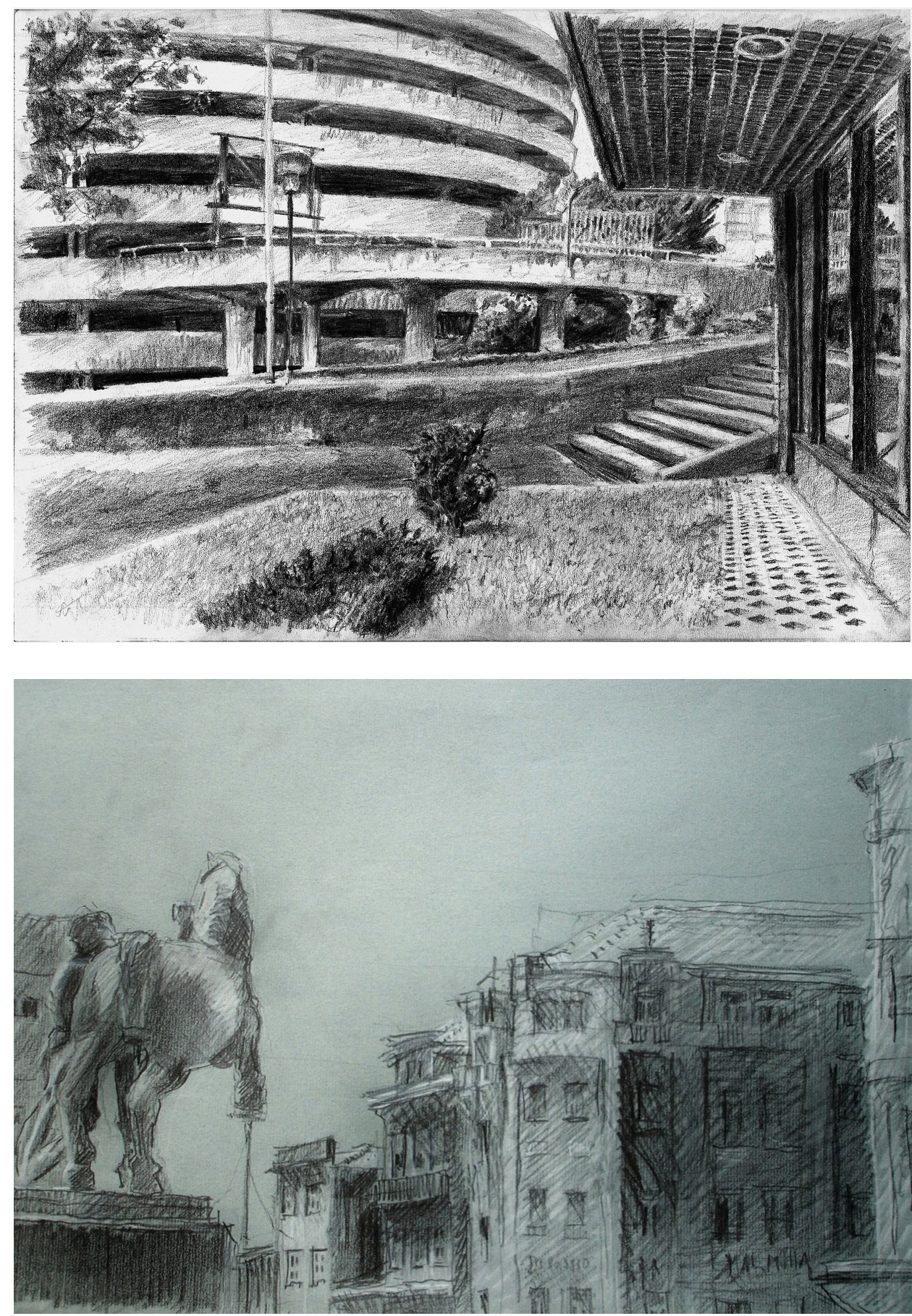

Figuras 11 e 12: Trabalhos da disciplina de desenho da FAUP. Fonte: Acervo do autor, 2012. 


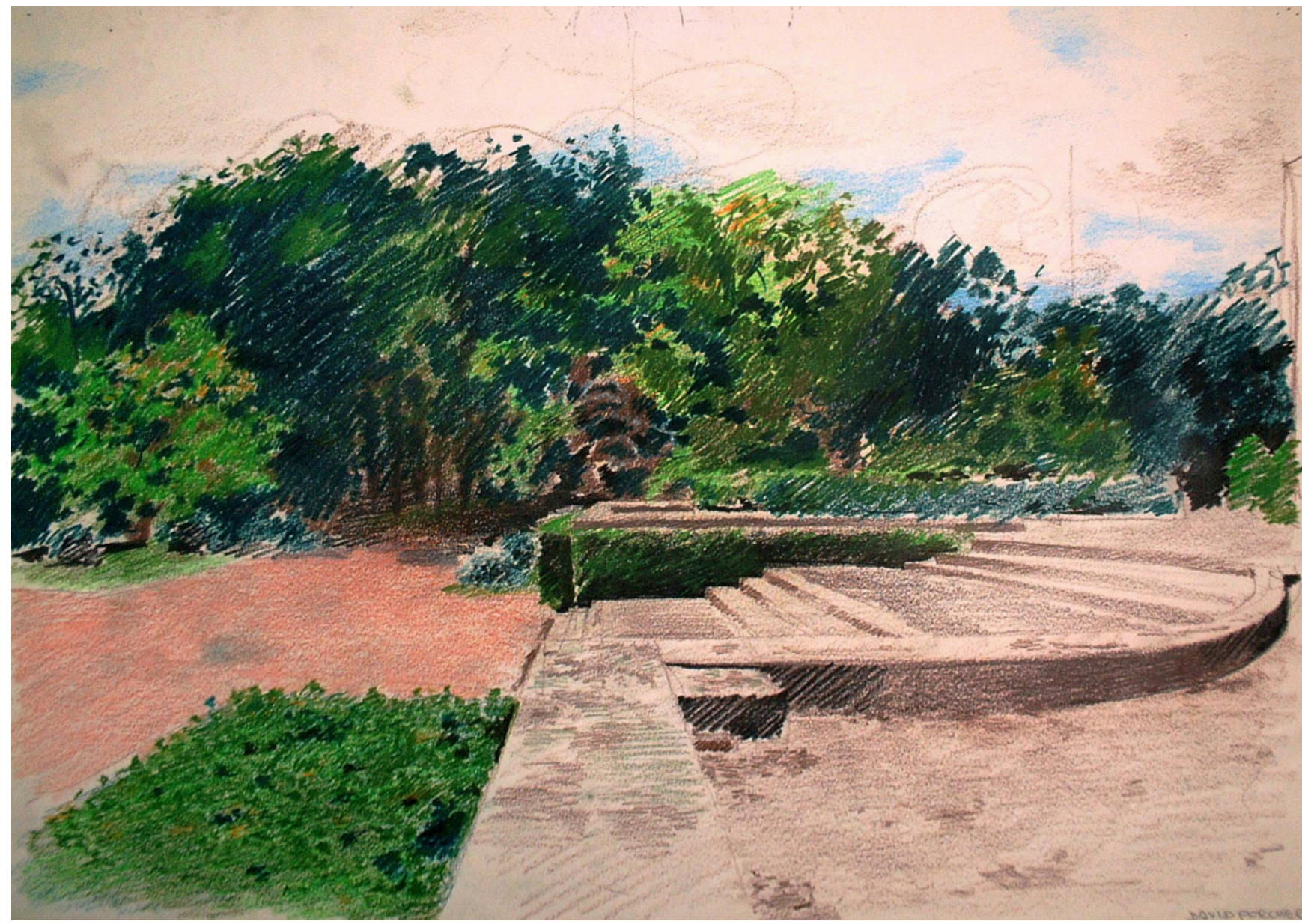

Figura 13: Trabalho da disciplina de desenho da FAUP. Fonte: Acervo do autor, 2012.

\section{Referências bibliográficas}

ARNHEIM, Rudolf. Arte \& percepção visual: uma psicologia de visão criadora. São Paulo: Pioneira, 1984

CÂMARA MUNICIPAL DE LISBOA. PELOURO DA CULTURA. Frederico George, Ver pelo desenho. Lisboa: Livros Horizonte, 1993.

GÓMEZ MOLINA, Juan José. Las lecciones del dibujo. Madrid: Cátedra, 1995. [D.59]

HALE, Robert Beverly. Drawing lessons from the great masters. New York: Watson-Guptill Publications, 1989.

MASSIRONI, Manfredo. Ver pelo desenho: aspectos técnicos, cognitivos, comunicativos. Lisboa: Ed. 70, 1983 